\title{
Neue Wege beschreiten
}

Liebe Leserin, lieber Leser,

wer hätte das noch bis vor Kurzem gedacht: Ein kleiner Krankheitserreger legt die komplette Welt lahm. Ganze Wirtschaftszweige mussten deswegen in Kurzarbeit gehen, andere hingegen machen Überstunden bis zum Umfallen. Die Coronakrise hat uns die Nachteile der modernen Welt aufgezeigt. So mussten Werke schließen, weil die Lieferketten zusammenbrachen, da Rohstoffe und Vorprodukte nur aus wenigen Quellen bezogen werden oder die Zulieferer in Übersee sitzen. In einigen Bereichen wird dies einen tiefgreifenden Wandel zu mehr Diversität bewirken, der Trend der Globalisierung ist gestoppt.

Die meisten Menschen verhalten sich vernünftig in dieser Krise. Abstände werden gewahrt, und wer Krankheitssymptome aufweist, begibt sich in Eigenquarantäne. Auch das Arbeiten hat sich vielerorts geändert: Wer konnte, arbeitete von zu Hause. Auch hier werden sich in vielen Bereichen nach der Pandemie Änderungen hin zu einem flexibleren Arbeitsort und flexibleren Arbeitszeiten ergeben.

Meinem Gefühl nach sind mehr Menschen bei dem schönen Wetter im Frühjahr im Grünen unterwegs. So begegneten mir abends bei Spaziergängen mit meinem Hund beispielsweise viel mehr Eltern mit Jugendlichen oder Fahrradfahrer als früher. Was sich nicht geändert hat, waren die vielen Landwirte bei der täglichen Arbeit auf dem Feld. „Die Nahrungsmittelversorgung ist auch in Krisenzeiten enorm wichtig. Deshalb wird uns Corona aus heutiger Sicht auch nicht so hart treffen wie andere Branchen“, sagt der Vorsitzende der Geschäftsführung von Agco/Fendt Christoph Gröblinghoff im Interview ab Seite 18. Eigentlich schwebten uns bei der Anfrage für das Interview Ende Januar 2020 andere Fragen vor. Doch dann holte uns Corona mit Macht ein, sodass wir den aktuellen Maßnahmen des Unternehmens breiten Raum widmeten.

Ich wünsche Ihnen viel Spaß beim Lesen der aktuellen Ausgabe Ihrer ATZheavyduty. Bleiben Sie gesund.
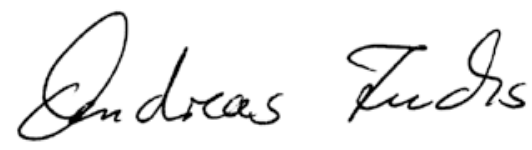

Andreas Fuchs

Verantwortlicher Redakteur

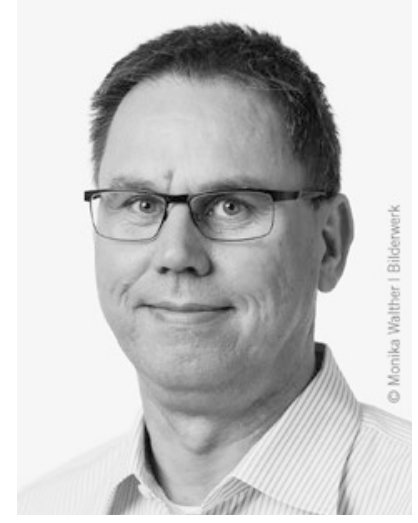

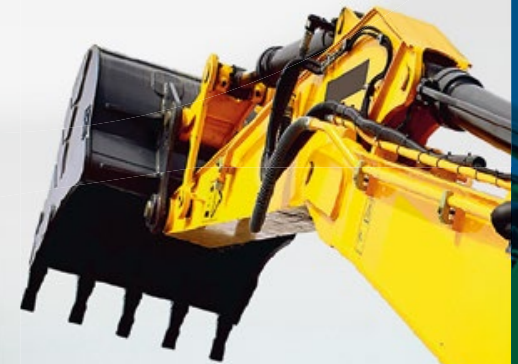

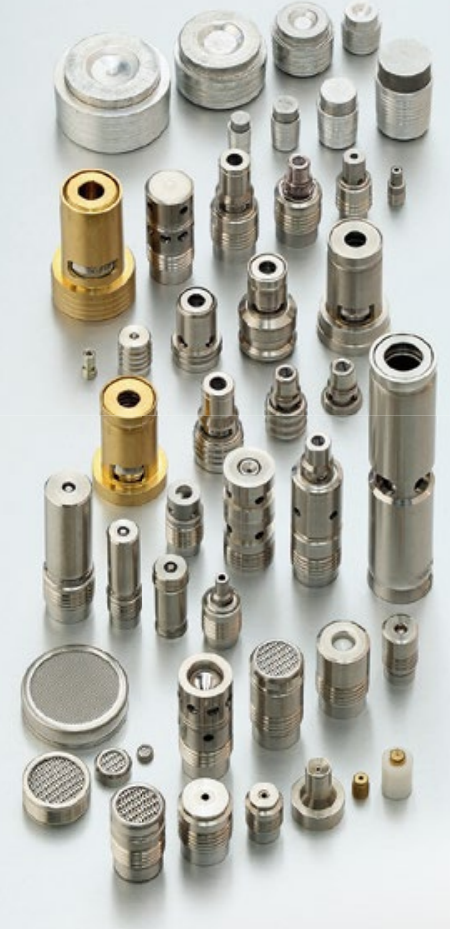

LEE Komponenten für die Industrie- und Fahrzeughydraulik $(\mathrm{IMH})$

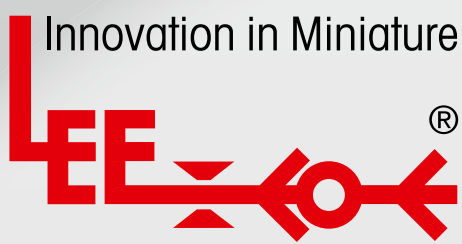

LEE Hydraulische

Miniaturkomponenten $\mathrm{GmbH}$ Am Limespark 2 - D-65843 Sulzbach

(c) $+49(0) 6196 / 77369-0$ info@lee.de www.lee.de 